\title{
Memória, Sociedade Florianopolitana e Elegância ${ }^{1}$.
}

\author{
Mara Rúbia Sant'Anna², Paula Consoni'.
}

Palavras-chave: Elegância - colunismo social - Florianópolis

Resumo: Como a dinâmica do colunismo social possibilitou não somente a visibilidade da elite como consolidou formas de parecer que construíram a subjetividade feminina. Explorou-se a eleição das "Dez mais elegantes" pelo cronista Zury Machado, nas décadas de 50 a 70. A partir de sua memória, de duas eleitas e duas mulheres que conviviam no mesmo espaço social, buscou-se os sentidos do ser elegante, interpretando que o mesmo confundia-se com uma aparência desejada.

Com o objetivo de analisar a dinâmica da conquista da aparência idealizada na consolidação de sujeitos do parecer e a construção da subjetividade feminina, a partir da escolha das dez mais elegantes, buscou-se a história oral como metodologia.

Segundo George P. Browne, num trabalho pioneiro editado no Brasil em 1974 a respeito do tema: "História oral é a designação dada ao conjunto de técnicas utilizadas na coleção, preparo e utilização de memórias gravadas para servirem de fonte primária a historiadores e cientistas sociais" (1974, 927). Para Alberti, responsável pela organização do "Manual de história oral” do CPDOC (Centro de Pesquisa e Documentação de História Contemporânea do Brasil) da Fundação Getúlio Vargas “a história oral é um método de pesquisa (histórica, antropológica, sociológica etc) que privilegia a realização de entrevistas com pessoas que participaram de, ou testemunharam, acontecimentos, conjunturas, visões de mundo, como forma de se aproximar do objeto de estudo" (ALBERTI, 2004, 18).

Seguindo esta perspectiva, entrevistamos um total de quatro mulheres, sendo duas participantes da lista das dez mais e o restante mulheres que conviviam nos mesmos ambientes públicos, mas que não foram eleitas. Anteriormente a realização das entrevistas, realizamos pesquisas sobre o colunismo social em Santa Catarina, já que o mesmo teve início no contexto do projeto de modernização do Estado e fazia parte do mesmo, quando analisado a partir da lógica cultural. Como instrumento de construção das elites e educação dos gostos diante do moderno, o

\footnotetext{
${ }^{1}$ Projeto de Pesquisa CEART/UDESC.

${ }^{2}$ Orientador, Professora do Departamento de Moda - Centro de Artes - Av. Madre Benvenuta, 1907 Itacorubi - CEP 88.035-001 - Florianópolis - SC.

${ }^{3}$ Acadêmica do Curso de Moda - CEART/UDESC, bolsista de iniciação científica do PROBIC/UDESC.

DAPesquisa, Florianópolis, v.2, n.4, p. 432-437, 2007.
} 
colunismo social conduziu a formação dos grupos de elite e funcionou como instrumento de poder destes, agenciando a almejada hierarquização social.

O ser parecido ${ }^{4}$, como caracteristíca de sua condição, precisou aparecer e os cronistas sociais ofereciam a vitrine transformando o parecido com um outro, o outro que alguém desejava parecer. Dentre as autoridades na dinâmica social estabelecida na exibição, no contexto florianopolitano, o cronista social Zury Machado é importante fonte histórica.

No início dos anos 50, no jornal "a Gazeta", o cronista estreou um estilo até então inexistente no Estado, onde, a exemplo dos cronistas paulistas e cariocas de sucesso, poderia possibilitar o aparecer que almejavam os exibidos ${ }^{5}$ da cidade. Em seguida de sua estréia passou ao jornal "O Estado", onde permanece publicando colunas diárias. Além de ter organizado eventos como bailes de debutantes e outros, que se tornaram eventos sociais indispensáveis a vida em sociedade.

Tendo alcançado importante visibilidade foi por muitas vezes convidado pelos colunáveis a jantares e coquetéis em sua homenagem que resultavam em notas na sua coluna no dia posterior. Transformando-se, portanto, em caminho obrigatório a quem desejava entrar para o grupo dos exibidos.

Iara Pedrosa surge no final da década de 60, como colunista, sendo também colunável. Sua coluna assemelhava-se a um diário, onde constavam dicas de beleza à culinária em um tom informal e fala direta ao leitor. Atraia os grupos menos privilegiados com pretensões de ascenção social, sendo um meio, talvez uma fresta, por onde aprendiam sobre o viver da elite e a constituiam como espelho a ser mirado e modelo a ser adotado.

A cronista era uma mulher moderna ${ }^{6}$, que falava aos modernos e abria espaço aqueles com a personalidade semelhante a dela. Se Zury se honrava honrando uma sociedade, que não se dispunha a ser vitrine todo o tempo, Iara se ocupava, especialmente, com essa.

Em 1962, Celso Pamplona no jornal “A Gazeta” passa, como o próprio dizia, a falar para os jovens. O cronista promovia shows de talentos e diversos bailes de debutantes e de gala, divertindo os filhos jovens da elite local e de muitas outras que haviam chegado na cidade.

Os cronistas sociais ao exaltar alguns por serem parecidos aos espelhos idealizados, mantinham a dinâmica da aparência como estratégia de existência social e essa, era reproduzida, na medida em que o aparecido seria sempre um parecido a consumir. Dentre esses, alguns foram

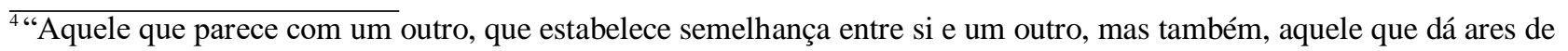
ser uma coisa ou que leva ao julgamento de ser, provavelmente, aquela coisa, aquela matriz de onde se parte para avaliar o visto" (SANT’ANNA, 2005, 624).

5 “... são aqueles que se tornaram um outro pelo consumo que fizeram de uma sociedade que se constituiu como existente a partir da mediação dos seres com as coisas, que constituiu o moderno, o que vale dizer novo, como sempre belo. (...) Como consumidos das coisas e, logo, de si, tornaram-se um ser parecido" (SANT'ANNA, 2005, 624). ${ }^{6}$ Mediada pelo desejo de ser um outro, uma imagem (valente) para manter-se na superficie (metáfora da realização desse projeto, pois representa a efemeridade que o caracteriza).
} 
eleitos e a prática de sua eleição evidenciava o quanto de poder social a aparência podia instituir aos que detinham considerável Capital-aparência.

Os aparecidos de Zury como os de Celso e Iara não eram plenos, não eram desprovidos de contradição, como todo o Sujeito-moda não o é, e experimentavam, todos, a aventura da modernidade. Uns, buscando a emersão, sem desprender-se de suas âncoras ${ }^{7}$, outros, emersos, em busca de uma notoriedade que os singularizassem e os fixassem, fazendo uso também do discurso da boa sociedade para parecerem o que desejavam.

O parecido a consumir era todo aquele que aparecesse freqüentemente, fosse na lista de presentes das ocasiões festivas, que familiarizava seu nome na memória dos leitores da coluna, fosse o belo rosto da jovem das capas do suplemento dominical, que dizia de uma elite que se reproduzia, fosse nas entrevistas ou matérias especiais, nas quais uma imagem de elite se firmava nas atividades filantrópicas que praticava, por suas casas decoradas com objetos de arte trazidos de todo o mundo, pela opção de trabalhar, que muitas das mulheres desse grupo faziam.

Mais uma prática de criar parecer era a lista das dez mais elegantes de Santa Catarina publicada por Zury Machado, no jornal “O Estado", que ao mesmo tempo legitimava a autoridade do colunista social em avaliar e hierarquizar a sociedade.

A primeira seleção ocorreu em 1954 e, em fevereiro de 1955, com grande pompa, numa festa organizada no restaurante do Lux Hotel, as escolhidas desfilaram e foram aplaudidas. O evento de caráter beneficiente foi considerado noite de grande gala e descrito como tal, reunindo várias figuras ilustres da cidade, tendo até 1958 mantido o mesmo formato.

Posteriormente, cada vez menos as eleitas queriam se dispor a desfilar e a festa de lançamento das dez mais elegantes foi se extinguindo. As escolhidas passaram a ser fotografadas para uma matéria especial, realizada através das páginas dos jornais e revistas. Acompanhavam as fotos legendas elogiosas, pequena descrição de suas vidas sociais e, logo, justificativas de porque tinham sido escolhidas. Tais matérias exclusivas apareciam no final do ano, quase sempre na edição de 25 de dezembro e ocupavam duas ou três páginas inteiras.

Zury, em entrevista, ativou em sua memória social que, a partir de 1970, foi cada vez menos conveniente realizar as listas e, nos primeiros anos daquela década, concluiu que não deveria mais realizá-las: "Todo mundo fazia e todo mundo era, se era chique, era rica e aí já era elegante, então, não tinha mais sentido fazer isso". A vitrine que Zury criara para exibir a elite que servia, tornou-se antiquada, não havia mais tantos curiosos por ela.

A eleição das dez mais elegantes perde o seu valor e motivo de existir, mas enquanto se mantinha como vitrine propagava, assim como as colunas sociais, as maneiras do ser elegante que confundiam-se com uma aparência desejeda e construíam a subjetividade feminina. Sendo assim, se

${ }^{7}$ Nome da família, ações filantrópicas, defesa da boa moral...

DAPesquisa, Florianópolis, v.2, n.4, p. 432-437, 2007. 
considera que o processo de subjetivação decorre das experiências de vida e da construção de significados a partir daquelas, o que, condicionado pela cultura, dá a positivação maior ou menor do vivido, o que se constrói como memória social.

Ao investigar este processo de subjetivação a análise da perspectiva dos sujeitos sociais do período foi imprescindível. Contudo, neste sentido, tinhamos a clareza de que a distância temporal entre a ação de testemunhar e a ação contada pela testemunha resulta no desafio de compreender a dinâmica da memória. Compreende-se a memória "não somente como construção, mas reconstrução através da duração que separa o momento rememorado do momento do relato" (FRANK, 1999,109).

Buscando trazer para o presente do relato as lembranças das entrevistadas, fizeram-se cartões de tendências de moda contendo breve descrição dos trajes e imagens ilustrativas, bem como cartões de política com imagens de presidentes e governadores da época, cartões de mídia destacando principais novelas, programas de televisão, rádio e revistas e os cartões de cultura trazendo artistas do período. Durante a realização das entrevistas, os mesmos foram apresentados às senhoras.

A partir de apontamentos e comentários sobre os cartões reafirmou-se que no começo dos anos 50 permanecia o significado instituído para a elegância pelo New Look, de Dior, de 1947: "muita discrição e uma feminilidade bastante marcada pela cintura estreita, pelos seios majestáticos, pelo tronco pouco enfatizado e em contrastes com a ampla saia. Uma mulher com proporções de boneca e sempre festiva" (SANT'ANNA, 2005, 335).

O conceito de elegância, adotado por Zury, no mesmo período, contemplava uma maneira de ser elite que implicava em vestir-se com bom gosto, ter peles, jóias caras e vestidos assinados em seu guarda-roupa, mas também em saber organizar recepções e receber com requinte e simpatia os convidados, ter uma casa bem decorada, participar de festas beneficentes, viajar pelo mundo, estar presente aos eventos sociais e, principalmente, denotar discrição e simplicidade de ser diferente como se a elegância fosse um estado natural da eleita.

Maggy Rouff escreveu o livro "La Philosophie de l'Élègance”, publicado em 1942, onde oferecia uma vasta definição do conceito de elegância. A autora também afirmava que a elegância exigia uma natureza, uma aptidão e um arsenal particular que somente reunido resultava naquele "ar superior que se reconhecia ao longe". Este argumento é ainda hoje repetido pelas entrevistadas quando questionadas sobre o que seria uma mulher elegante, fato este que evidencia uma internalização dos conceitos lidos na juventude.

Com a consolidação do parecer como lógica social o campo de produção das mercadorias vinculadas à dimensão estética adquiriu um mercado altamente afoito e competitivo. O surgimento 
do Prêt-à-porter, nos anos 60, está intimamente ligado a esta questão, coroando o novo como ícone de uma geração.

A elegância, neste contexto, adquiriu um novo qualificativo, que desbancava o luxo a que o glamour da elegância anterior se referia, a sofisticação com certa irreverência e ludicidade. Zury, inclusive, nas considerações prévias das listas passou a exaltar os aspectos morais de boa mãe, esposa, pessoa filantropa e da capacidade de receber os convidados.

Quanto mais o padrão da elegância mudava mais a estratégia de ser uma exigia de sua pretendente a competência de ser um outro, fazendo parecer sempre a mesma. Nos fins de 60, a beleza poderia ser construída conforme os gostos - vida profissional e objetivos de vida - estando ao alcance de todas. Ser uma nova mulher era se vestir do novo, ter equilíbrio, saber contrabalançar os opostos ou extremos.

A aceitação do novo que "os ventos" do moderno traziam, conduzia consigo a necessidade de abrir-se a um novo que jamais seria velho; que deveria, para ser realmente novo, ser sempre renovado, efêmero e, assim, quem quisesse ser moderno, como nas cidades cosmopolitas podia-se ser, precisava perder a timidez e se dispor, continuadamente, a viver o inesperado, a permanecer na superfície.

Uma nova relação dialógica entre cronista e leitor menos impositiva nas considerações sobre elegância e preocupada em divulgar as tendências e ensiná-las aos consumidores, bem como apresentá-las através dos editoriais de moda marcava o borbulhar dos novos tempos.

No contexto destas transformações a lista das dez mais perde o sentido de existir. Com a configuração de seres pautados na aparência e sendo esta mutável, pois moderna, as âncoras que sustentavam as justificativas da eleição quebram-se com o peso desta modernidade. Mesmo a entrevistada 1, uma das eleitas, quando indagada sobre a possibilidade de haver ainda hoje uma eleição neste mesmo gênero, respondeu sorrindo que considerava "fora de contexto".

Nos ditos e não-ditos mais do que relatos pessoais as entrevistas eram narrações do vivido que levaram-nos a caminhos diversos onde a aparência da elegância confundia-se com o ser elegante, porém nossa preocupação não esteve em separá-los ou rotulá-los, e sim direcioná-los para o entendimento da construção da subjetividade feminina. Neste sentido, entendemos que ao repetir o discurso dos colunistas sociais do período no que tange a noção de elegância em seus gestos e falas revelavam a importância destas colunas na constituição destas mulheres.

Seguindo a lógica da elegância como algo natural, intrínseco, constatamos certo descaso por parte das eleitas quanto a listas das dez mais, uma vez que elas consideram-se naturalmente elegantes não precisando de tal aval ou apontamento. Sendo assim, a repercussão da eleição não tem a consistência inicialmente pensada, pois, inclusive, as mulheres da sociedade avaliaram a eleição como maquiada e influenciada pela posição social da eleita.

DAPesquisa, Florianópolis, v.2, n.4, p. 432-437, 2007. 
O ser elegante, deste contexto histórico, encontra suporte em um capital-aparência adequado, mas principalmente na influência familiar como perpetuação de maneiras. Porém, estes espelhos sociais aliados a modernização catarinense tornam possível obter uma aparência idealizada e é, neste sentido, que se percebe a valorização do parecer, logo a construção de uma sociedade de moda.

\section{Referências bibliográficas:}

ALBERTI, Verena. Manual de História Oral. Rio de Janeiro: Editora FGV, 2004.

BERGSON, Henri. Matéria e memória. São Paulo: Martins Fontes, 1990.

BOSI, Ecléa. Memória e sociedade. São Paulo: EDUSP, 1987.

BROWNE, George P ; PIAZZA, W. A documentação em História Oral. 1974 [manuscrito]

FRANK, Robert. Questões para as fontes do presente. In: CHAUVEAU, Agnes. Questões para a

história do presente. Bauru: Edusc, 1999.

SANT'ANNA, Mara Rúbia. Aparência e poder : novas sociabilidades urbanas, em

Florianópolis, de 1950 a 1970 / 2005. 